\title{
BENZENE SOURCE APPORTIONMENT USING BIVARIATE CORRELATION AND REGRESSION ANALYSES
}

\author{
Mirjana Perišić ${ }^{1,2 *}$, \\ Gordana Jovanović1,2, \\ Ana Vranić ${ }^{1}$, \\ Svetlana Stanišić ${ }^{2}$ \\ ${ }^{1}$ Institute of Physics Belgrade, National \\ Institute of the Republic of Serbia, \\ University of Belgrade, \\ Belgrade, Serbia \\ ²Environment and Sustainable Development, \\ Singidunum University, \\ Belgrade, Serbia
}

\begin{abstract}
:
The aim of this study was to identify and characterize the individual sources of benzene in an urban area of Belgrade based on bivariate polar plot concentration, correlation, and regression analyses. The presented benzene behavior modeling relied on a weighted Pearson correlation coefficient, linear regression slope, and Gaussian kernel locally weighted by wind speed direction surface. The data, including the concentrations of volatile organic compounds (VOCs), inorganic gaseous pollutants and meteorological parameters, were obtained from a measurement campaign conducted at the Singidunum University (Belgrade, Serbia) during and after the heating season 2016. The results indicate the dominance of benzene, toluene, and NO local emission sources, as well as the significant impact of remote $\mathrm{NO}_{2}$ sources located in the SW and SE. The strong interrelations between VOCs indicate the common origin of these compounds. High toluene to benzene ratio $(>2)$ was almost independent of wind speed and direction, indicating that the entire area was severely exposed to fresh vehicular emissions. The absence of relationships between benzene and fossil fuel combustion gaseous pollutants including $\mathrm{NO}_{x}$ and $\mathrm{O}_{3}$ suggests that evaporations from small chemical industrial complex situated in the $S$ direction from the study site might be the main benzene and toluene emission source in the area. As regards inorganic gaseous pollutants, the relationship between benzene and NO in the $\mathrm{N}$ and NE might be related to the intensive anthropogenic activities in the central urban area of Belgrade and petrochemical industry in Pančevo. As presented herein, a combination of bivariate polar plot concentration, correlation, and regression analyses offers unique insight into the individual sources of air pollutants and their concentration dynamics.
\end{abstract}

Keywords:

benzene, volatile organic compounds, bivariate polar plot analysis.

\section{INTRODUCTION}

In the recent years, volatile organic compounds (VOCs) became an important environmental issue because of their harmful impacts on human health and the environment. They originate from numerous natural and anthropogenic sources and are involved in a wide range of chemical reactions in the atmosphere including the formation of secondary 
organic aerosols and tropospheric ozone. The most abundant VOCs in the atmosphere are hydrocarbons, organic alcohols, halogenated organic compounds, and sulfur compounds [1]. Four aromatic hydrocarbons benzene, toluene, ethylbenzene, and xylene, commonly known as a BTEX group, are found to be abundant in the urban atmosphere and are considered the representatives of volatile organics [2,3]. Natural sources of BTEX include crude oil evaporations and emissions from volcanoes and forest fires, while the primary anthropogenic emissions of BTEX compounds are related to motor vehicles, cigarette smoke, petroleum products, and the production and use of paints, lacquers, thinners, rubber, cosmetics, and pharmaceutical products [4].

Among the BTEX, benzene draws special attention because it is considered to be the most toxic and detrimental compound [5]. The International Agency for Research on Cancer (IARC), classified benzene as carcinogenic compound to humans (Group 1), while ethylbenzene has assigned as probably carcinogenic (Group 2). There is no evidence of the toluene and xylenes carcinogenicity in humans (Group 3), but toluene is more soluble in lipids than benzene, and therefore toluene exposure can lead to adverse neurological effects [6].

The research aimed at the investigation of VOC emission sources has been intensified over the last two decades, and many of these studies have been focused on the identification of sources by estimating the ratios of BTEX concentrations in the ambient air and calculating their correlations $[7,8]$. Toluene to benzene ratio is commonly used to distinguish the impact of traffic and non-traffic emission sources, while ethylbenzene to benzene ratio, as well as xylenes to benzene ratio are often applied as indicators of photochemical reaction intensity [9].

This study considered the relationships and ratios between benzene, and toluene and inorganic pollutants, in the context of simultaneously measured meteorological parameters, wind speed and wind direction. The bivariate polar plot method in a combination with pairwise statistics was used to indicate the most significant emission sources of benzene and investigate their characteristics in an urban area.

\section{MATERIAL AND METHODS}

For the purpose of this study, the measurements were conducted over the three-months period, at the Singidunum University building in the urban area of Belgrade (Serbia) during and after the heating season of 2016. The dataset comprised the concentrations of air pollutants and meteorological parameters [10].
University building is surrounded by large residential areas from W, SW, and NE side, some of which encompass households with individual fireboxes, while small scale industry referring to Road Institute of Belgrade, a building company and beverage factory stockroom are located in the nearest vicinity. In addition, confectionery factory, footwear factory, and several small-scale chemical plants are located $600 \mathrm{~m}$ in the NW and S direction, respectively. Approximately $800 \mathrm{~m}$ to the $\mathrm{W}$ and SW from the measurement site a large district heating plant and fuel oil heating plant of urban forestry organization used for the purposes of planting material production are situated. A boulevard with public transport and moderate vehicle flow passes by approximately $250 \mathrm{~m}$ in the SW direction, while a road with intense traffic is about $500 \mathrm{~m}$ away in the $\mathrm{W}-\mathrm{NW}$ direction. The old city center and river confluence are located at the distance exceeding $2 \mathrm{~km}$ in the NW direction.

During the campaign, besides the other pollutants including polycyclic aromatic hydrocarbons, gases and metals, the concentrations of benzene, toluene, nitrogen oxides ( $\mathrm{NO}, \mathrm{NO}_{2}$, and $\left.\mathrm{NO}_{\mathrm{x}}\right)$, ozone $\left(\mathrm{O}_{3}\right)$, and meteorological parameters, including wind characteristics, were collected. The VOCs concentrations were measured in real time using a proton transfer reaction mass spectrometer (Standard PTR-MS, Ionicon Analytik, GmbH, Austria). A detailed description of the PTR-MS method is given elsewhere [11], while calibration procedure was done according to Taipale et al. [12]. Inorganic gaseous pollutant measurements were conducted by using Horiba 370 series devices which enabled continual pollutant concentration monitoring with a 2 minute-resolution data. The APNA-370 device was used for $\mathrm{NO}_{\mathrm{x}}$ concentration measurements by a combination of dual crossflow modulation type chemiluminescence principle and the referential calculation method according to SRPS EN 14211:2013 standard. Continuous monitoring of ozone concentrations was performed by the cross-flow modulated ultraviolet absorption method using APOA370 device according to standard SRPS EN 14625:2013. Meteorological data were obtained by using Vaisala weather station (Weather Transmitter WXT530 Series).

The statistical data analyses included bivariate polar plots, and improved analytical method which combines bivariate polar plots with pair-wise statistics that provide information on how two pollutants are related to one another. The pair-wise statistics implemented include the weighted Pearson correlation and slope from two linear regression methods. More details about this method can be found in Grange et al. [13, 14]. 
The analyses were performed with the statistical software environment R [15], by the use of the Openair package [16].

\section{RESULTS AND DISCUSSION}

As indicated by the elevated pollutant concentrations at low wind speeds $\left(<1 \mathrm{~m} \mathrm{~s}^{-1}\right)$, there is a dominance of local traffic emissions of benzene, toluene, and NO in the nearest vicinity of the sampling site (Fig. 1).
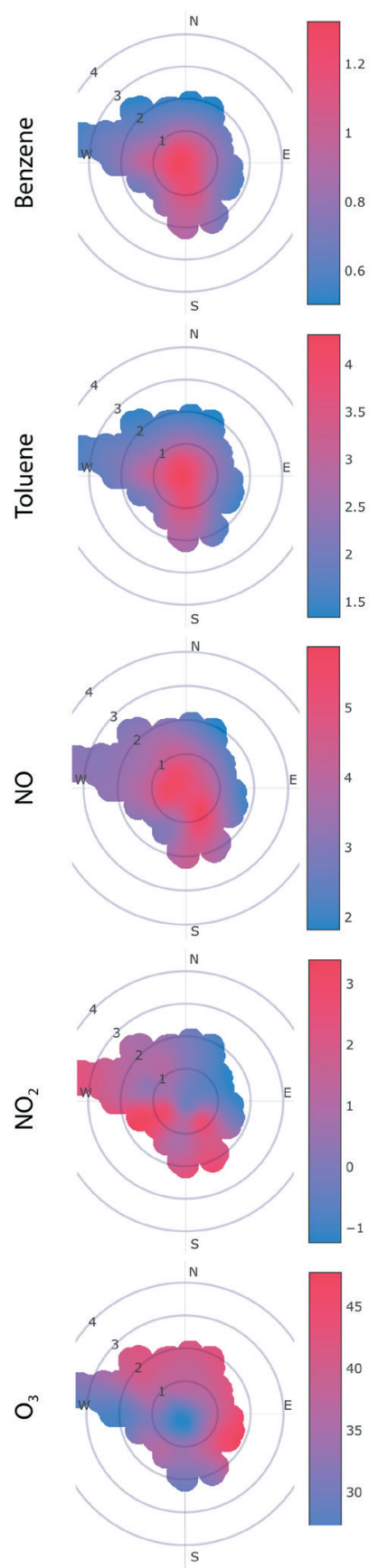

Fig. 1. Bivariate polar plot of benzene, toluene, $\mathrm{NO}, \mathrm{NO}_{2}$, $\mathrm{NO}_{x}$, and $\mathrm{O}_{3}$.
The highest concentrations $\left(>3 \mu \mathrm{g} \mathrm{m}^{-3}\right)$ of $\mathrm{NO}_{2}$ were recorded during $S$ and $S W$ wind episodes which caused the air pollution transport from distant sources including the powerplants "Nikola Tesla" and "Kolubara" situated in Obrenovac and Veliki Crljeni [17]. In addition, several sources of $\mathrm{O}_{3}$ were observed, and the dominant ones contributing to the concentrations higher than 40 $\mu \mathrm{g} \mathrm{m}^{-3}$ were identified in $\mathrm{N}, \mathrm{E}$, and SE direction of the measurement site.

Photochemical formation of $\mathrm{O}_{3}$ in the troposphere is facilitated by the presence of sunlight and elevated levels of precursor pollutants including $\mathrm{NO}_{\mathrm{x}}$ and VOCs.

The correlation matrix shows that the two organic compounds, benzene and toluene, were well correlated $(\mathrm{r}=0.96)$ (Fig. 2), which might suggest their common origin [18]. However, this type of analysis does not provide an indication of which type of source and to what extent contributes to total benzene concentrations. No significant relationships between benzene and $\mathrm{NO}, \mathrm{NO}_{2}, \mathrm{O}_{3}$, and wind parameters were registered although very low values of Pearson's correlation coefficient $(r=0.29)$ between benzene and NO could be an indication of common pollutant emission sources, probably one of them being fossil fuel combustion.

When the benzene and other pollutant concentrations were plotted with a correlation statistic and slope binned by wind speed and direction (Fig. 3), the results were revealing more than the mean concentration polar plots and the correlation matrix together.

The strong relationship between benzene and toluene indicates the same dominant source of these compounds. The polar plot of the slope shows that the high toluene to benzene ratio $(>2)$ was almost independent of wind speed and direction, indicating that the whole area was severely exposed to fresh vehicular emission sources [19]. Furthermore, during the $\mathrm{N}$ winds (NE and $\mathrm{NW}$, more precisely), benzene and $\mathrm{NO}$ were highly correlated.

The zones of high correlation and the relationship between benzene and $\mathrm{NO}$ (slope $>6$ ) in the $\mathrm{N}$ and $\mathrm{NE}$ indicate the impact of intensive anthropogenic activities in the central urban area of Belgrade and petrochemical sources near Pančevo [20].

The absence of a relationship between benzene and fossil fuel combustion gaseous pollutants including nitrogen oxides and $\mathrm{O}_{3}$ indicated that benzene and toluene evaporations from small chemical industry complexes situated in the $S$ direction from the study site can be considered the main pollution source in the area. 


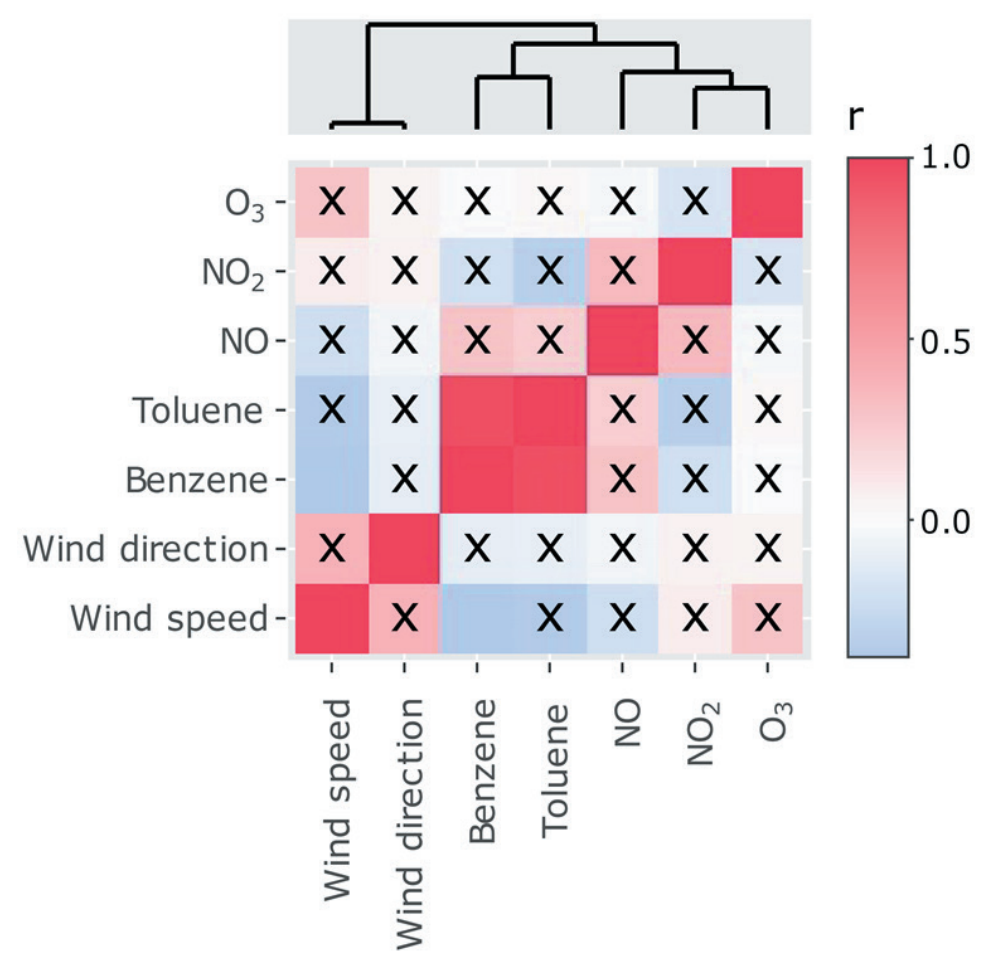

Fig. 2. Correlation matrix of pollutant concentrations and wind parameters.
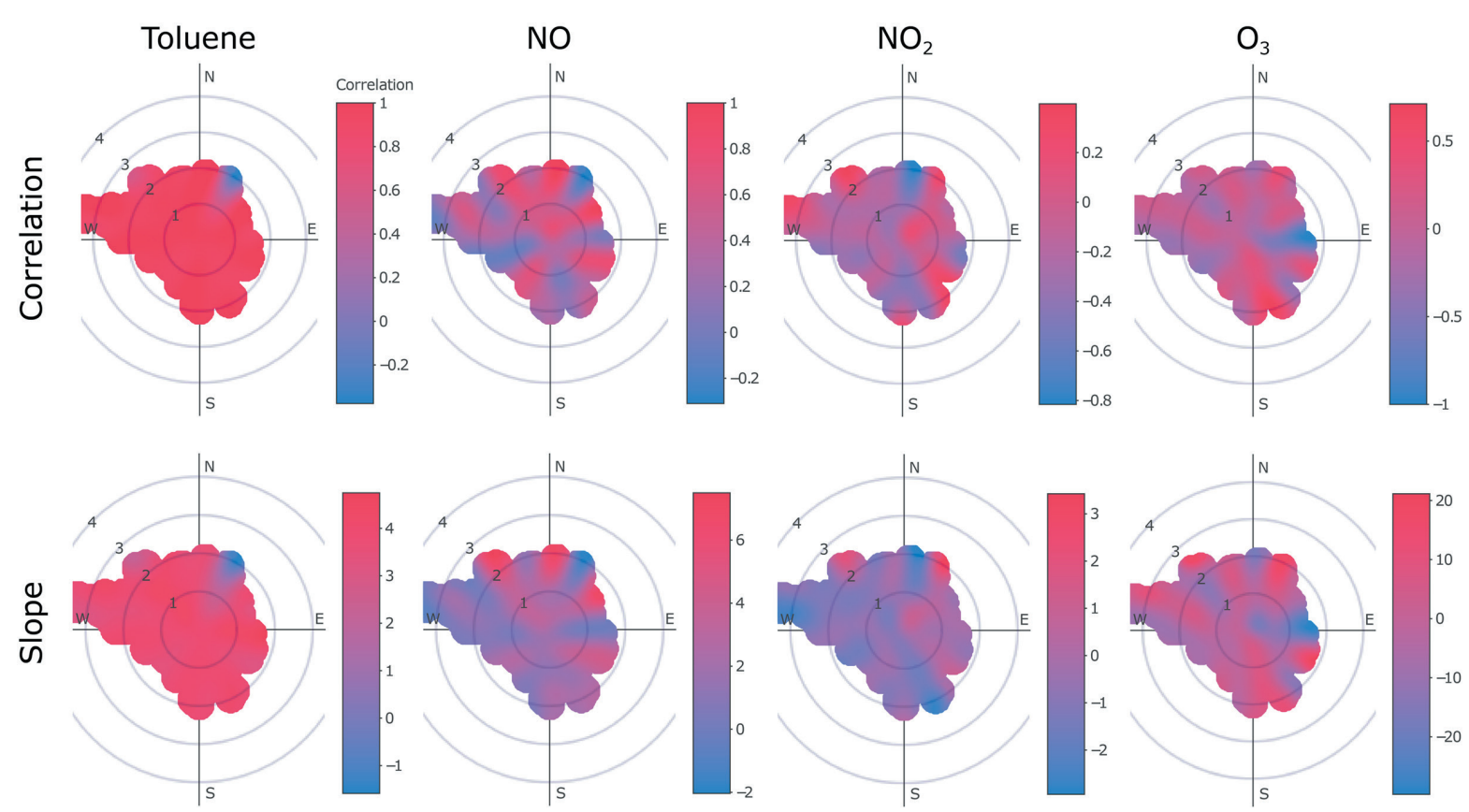

Fig. 3 Polar plot of the correlation (above) and slope (down) between benzene and toluene, $\mathrm{NO}, \mathrm{NO}_{2}, \mathrm{NO}_{\mathrm{x}}$, and $\mathrm{O}_{3}$ 


\section{CONCLUSION}

In the field of atmospheric and environmental science, research on the relationship between chemical pollutants in the air and meteorological parameters is tremendously common, and there are diverse techniques of determination of the relationship and comparison. An analysis that also takes into account the correlation of the two pollutants can often be useful because it can lead to the identification of emission source characteristics.

Statistical analysis that includes wind characteristics - bivariate polar plot, applied to the concentrations of benzene, toluene, nitrogen oxides, and ozone, suggests that local sources of air pollution dominate in the study area. With pollutants mainly originating from local emissions, the elevated concentrations occur due to the lack of dispersion, in cases where wind speeds are low $\left(<1 \mathrm{~m} \mathrm{~s}^{-1}\right)$. Polar correlations and slopes indicate that there were several types of sources that affected benzene concentrations in the investigated area, and the most important include exhaust from motor vehicles and emissions from industrial processes.

In addition to the statistical receptor modeling, analysis related to spatio-temporal variations and the contribution of other species and sources is required for reliable identification of benzene sources in complex atmospheric environments. The accompanying study should focus on factors such as the pattern of the weekend/weekday activities, regional and long-range transport, planetary boundary layer dynamics, and others meteorological parameters that significantly affect the observed VOC concentrations.

\section{ACKNOWLEDGMENT}

The authors acknowledge funding provided by the Science Fund of the Republic of Serbia \#GRANT No. 6524105, AI - ATLAS.

\section{REFERENCES}

[1] X. Zhang, B. Gao, A. E. Creamer, C. Cao and Y. Li, "Adsorption of VOCs onto engineered carbon materials: A review", Journal of hazardous materials, 338, 2017, pp.102-123.

[2] R. Montero-Montoya, R. López-Vargas and O. Arellano-Aguilar, "Volatile organic compounds in air: sources, distribution, exposure and associated illnesses in children", Annals of global health, 84(2), 2018, pp. 225.

[3] A. Mohammadi, Y. Ghassoun, M.O. Löwner, M. Behmanesh, M. Faraji, S. Nemati, ... and M. Miri, "Spatial analysis and risk assessment of urban BTEX compounds in Urmia, Iran", Chemosphere, 246, 2020, pp. 125769.

[4] F. Hedayatzade and N. Hassanzadeh, "Occurrence, Probable Source, and Health Risk Assessment of Benzene, Toluene, Ethylbenzene, and Xylene Compounds in Ambient Urban Atmosphere in Ahvaz, Iran", Archives of Hygiene Sciences, 9(2), 2020, pp. 152-167.

[5] US EPA 2002. "Toxicological review of benzene (noncancer effects)", In Support of Summary Information on the Integrated Risk Information System (IRIS), U.S. Environmental Protection Agency, Washington, DC, October 2002

[6] IARC, 2014," Monographs on the Evaluation of Carcinogenic Risks to Humans", World Health Organization, International Agency for Cancer Research, Internal Report 14/002, Lyon.

[7] M. Dehghani, M. Fazlzadeh, A. Sorooshian, H. R. Tabatabaee, M. Miri, A. N. Baghani, ... and M. Rashidi, "Characteristics and health effects of BTEX in a hot spot for urban pollution", Ecotoxicology and environmental safety, 155, 2018, pp. 133-143.

[8] Z. Jiang, B. Grosselin, V. Daële, A. Mellouki and Y. $\mathrm{Mu}$, "Seasonal and diurnal variations of BTEX compounds in the semi-urban environment of Orleans, France", Science of The Total Environment, 574, 2017, pp. 1659-1664.

[9] B. T. Thera, P. Dominutti, F. Öztürk, T. Salameh, S. Sauvage, C. Afif, ... and A. Borbon, "Composition and variability of gaseous organic pollution in the port megacity of Istanbul: source attribution, emission ratios, and inventory evaluation", Atmospheric Chemistry \& Physics, 19(23), 2019.

[10] S. Stanišić, M. Periš̌ć, G. Jovanović, T. Milićević, S. Herceg Romanić, A. Jovanović, A. Šoštarić, V. Udovičić and A. Stojić, "The PM2.5-bound polycyclic aromatic hydrocarbons: the identification of emission sources and XGBoost pollutant level prediction in indoor and outdoor environment", 2020. (submitted for publication) 
[11] W. Lindinger, A. Hansel and A. Jordan, "On-line monitoring of volatile organic compounds at pptv levels by means of proton-transfer-reaction mass spectrometry (PTR-MS) medical applications, food control and environmental research", International Journal of Mass Spectrometry and Ion Processes, 173(3), 1998, pp.191-241.

[12] R. Taipale, T.M. Ruuskanen, J. Rinne, M.K. Kajos, H. Hakola, T. Pohja and M. Kulmala, "Quantitative long-term measurements of VOC concentrations by PTR-MS? measurement, calibration, and volume mixing ratio calculation methods", 2008, hal. archives-ouvertes.fr.

[13] S. K. Grange, A. C. Lewis and D.C. Carslaw, "Source apportionment advances using polar plots of bivariate correlation and regression statistics", Atmospheric Environment, 145, 2016, pp. 128-134.

[14] W. Javed, M. Iakovides, E. G. Stephanou, J. M. Wolfson, P. Koutrakis and B. Guo, "Concentrations of aliphatic and polycyclic aromatic hydrocarbons in ambient PM2.5 and PM10 particulates in Doha, Qatar”, Journal of the Air \& Waste Management Association, 69(2), 2019, pp. 162-177.

[15] Team, R. C. (2012). R: A language and environment for statistical computing. 2012. Vienna, Austria: R Foundation for Statistical Computing, 10.
[16] D. C. Carslaw and K. Ropkins, "Openair-an R package for air quality data analysis", Environmental Modelling \& Software”, 27, 2012, pp. 52-61.

[17] M. Perišić, A. Stojić, S. S. Stojić, A. Šoštarić, Z. Mijić and S. Rajšić, "Estimation of required PM 10 emission source reduction on the basis of a 10-year period data", Air Quality, Atmosphere \& Health, 8(4), 2015, pp. 379-389.

[18] A. Stojić, S. S. Stojić, Z. Mijić, A. Šoštarić, and S. Rajšić, "Spatio-temporal distribution of VOC emissions in urban area based on receptor modeling", Atmospheric Environment, 106, 2015, pp. 71-79.

[19] B. T. Thera, P. Dominutti, F. Öztürk, T. Salameh, S. Sauvage, C. Afif, ... and A. Borbon, "Composition and variability of gaseous organic pollution in the port megacity of Istanbul: source attribution, emission ratios, and inventory evaluation", Atmospheric Chemistry \& Physics, 19(23), 2019.

[20] A. Stojić, D. Maletić, S. S. Stojić, Z. Mijić and A. Šoštarić, "Forecasting of VOC emissions from traffic and industry using classification and regression multivariate methods", Science of the Total Environment, 521, 2015, pp. 19-26. 